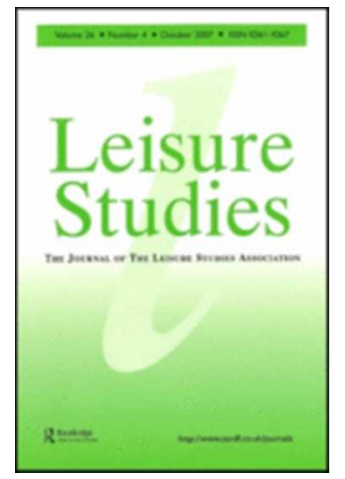

\title{
Internal migration, sport and the Scottish diaspora in England
}

\begin{tabular}{|r|l|}
\hline Journal: & Leisure Studies \\
\hline Manuscript ID: & RLST-2013-0182.R1 \\
\hline Manuscript Type: & Original Paper \\
\hline Keywords: & $\begin{array}{l}\text { sport, Scotland, Scottish diaspora, England, internal migration, national } \\
\text { identity }\end{array}$ \\
\hline \multicolumn{2}{|l}{} \\
\hline
\end{tabular}

SCHOLARONE ${ }^{\text {IM }}$

Manuscripts 


\section{Abstract}

Sport has been argued to play an important role for members of diasporic groups of various origins and in various locations (Burdsey, 2006; Carrington, 2010; Darby and Hassan, 2008; Kaufman, 2005). However, little attention has been paid to the role sport plays for 'internal migrants' who migrate to contrasting locations within a nation-state, despite the potential for significant contrasts in the prevailing sporting cultures found in different regions of the same nation-state. This article therefore aims to make a contribution towards understanding this relationship by reflecting upon the role sport plays for members of the Scottish diaspora living in England, drawing upon interviews and personal reflections from a number of Scottish 'internal migrants' located within the United Kingdom. In particular, discussion attempts to draw attention to the central role sport plays for these individuals in order to maintain a cultural attachment with their Scottish birthplace, given the relative lack of other cultural practices or associations which could be used to achieve this goal. Comparisons are also drawn with studies of the Scottish diaspora in more distant geographic contexts, as well as similar diasporic groups in the English context such as the Irish diaspora. These comparisons allow for a consideration of the impact of geographic proximity and cultural proximity on the relative importance of sport and other cultural practices for Scots living in England, identifying a number of important issues for those studying the role played by sport in the maintenance of a cultural attachment with 'home' for various diasporic groups.

Keywords: sport, Scotland, Scottish diaspora, England, internal migration, national identity

\section{Introduction}

Sport has been argued to play an important role for members of diasporic groups of various origins and in various locations (Burdsey, 2006; Carrington, 2010; Darby and Hassan, 2008; Kaufman, 2005). Such studies have frequently identified the potential benefits derived from 
engagement with sport for migrants with regards to maintaining cultural links with 'home', whether through sports media consumption (whether individually or collectively), the opportunity sport can provide to socialise with fellow members of a particular diaspora, or the possibility to import and recreate 'authentic' sporting and non-sporting cultures from one's original homeland in their new 'host' setting (Darby and Hassan, 2008; Giulianotti, 2005; Giulianotti and Robertson, 2006, 2007; Kaufman, 2005). Furthermore, sport can act as a site for challenging the dominant political, cultural and social attitudes in both the 'host' and 'home' nations (Darby and Hassan, 2008; Kaufman, 2005). Sport can therefore act as one barometer for gauging the extent to which a migrant or migrant group is culturally integrated, assimilated, accommodated or segregated in their host country.

The majority of research into the relationship between sport and migration has understandably deployed the 'nation-state' as the frame of reference for their identification of diasporic groups, therefore focusing on migrants who have moved from their 'home' nation-state to an alternative 'host' nation. This approach aligns with the original definitions and conceptualisations of the term 'diaspora' in academic writing in the field (Braziel and Mannur, 2003; Cohen, 2008; Safran, 1991), and has been undeniably fruitful in exploring the multifarious roles sport can (and cannot) play for members of diasporic groups. However, interventions in the definitional debate regarding the term 'diaspora' such as those by Brubaker (2005) have illustrated the 
"dispersion of the meanings of the term in semantic, conceptual and disciplinary space" (ibid: 1). This dispersion has therefore been argued to have facilitated a consideration of diasporic groups who have migrated to locations within the same nation-state (Brubaker, 2005). Nonetheless, less attention has been paid to the role sport plays for 'internal migrants' who migrate to contrasting locations within a nation-state, despite the potential for significant contrasts in the sporting culture between different regions of the same nation-state. The contrasts in sporting culture within a nation-state can be caused by numerous geographic factors (e.g. urban or rural surroundings; proximity to coastlines, lakes and rivers for watersports; proximity to mountainous areas for winter sports and adventurous activities), socioeconomic factors (e.g. relative regional levels of disposable income; class-based sporting preferences) and sociocultural factors (e.g. local and regional sporting identities; cultural, religious and ethnic diversity of location). Given the potential contextual variability within a nation-state, further consideration of the role of sport for 'internal migrants' who relocate to settings within their 'home' nation-state offers the possibility to provide a more nuanced understanding of the relationship between sport and migration.

This article therefore aims to make a contribution towards understanding this relationship by reflecting upon the role sport plays for members of the Scottish diaspora living in England. Approximately 800,000 individuals born in Scotland reside in England, representing twothirds of the estimated 1.25 million Scots-born migrants who reside 
outside of Scotland (Ancien, Boyle and Kitchin, 2009; Sim, 2011a). Given that the United Kingdom as a nation-state is constituted of England, Scotland, Wales and Northern Ireland, Scots living in England can be viewed as 'internal migrants' within the United Kingdom nationstate (Fielding, 2012; Finney and Simpson, 2008). This article will therefore explore the experiences of Scots living in England in relation to their sporting and wider cultural habits, drawing upon interviews and personal reflections from a variety of participants. Before turning attention to the role sport plays for these individuals, however, consideration will firstly be given to past studies of the Scottish diaspora in various geographic locations, before honing in on literature discussing the specific context of England and, finally, the importance of sport to the Scottish diaspora.

\section{The Scottish Diaspora}

Braziel and Mannur (2003) argue that the sociological study of diasporic groups is of analytical interest as their migration and assimilation to an alternative culture results in the production of hybrid identities and multiple belongings which undermine traditional conceptualisations of identity. Following the establishment of the devolved Scottish Parliament in 1999, there has been an increase in the number of academic studies concentrating on the Scottish diaspora following the development of a number of diaspora engagement policies supported by the devolved Scottish Executive (Sim, 2012). Support for 
diaspora engagement has been further boosted since the rebranding of the 'Scottish Executive' to the 'Scottish Government' following the rise to power of the Scottish National Party (SNP) in 2007 as a minority government and in 2011 as a majority government, with the SNP embracing the opportunity to support the Scottish tourism industry by encouraging members of the Scottish diaspora across the world to visit Scotland, whilst simultaneously boosting Scottish exports (Mycock, 2012; Sim, 2012).

However, given the lack of sovereign statehood for the Scottish 'nation', the case of the Scottish diaspora generates some analytical difficulties in relation to the application of key concepts and typologies derived from the academic study of other diasporic groups (Devine, 2011). For example, Cohen's (2008) typology of classic diasporas identifies categories such as 'victim' (e.g. Jews, Africans), 'labour' (e.g. indentured Indians), 'imperial' (e.g. British), 'trade' (e.g. Lebanese, Chinese) and 'deterritorialised' (e.g. Caribbean peoples, Parsis) diasporas. Whilst certain elements of this typology can be applied to Scottish emigrants and diasporic groups with regards to labour as a motivating force for emigration, it is difficult to draw clear analogies along these categorical lines in the way that it is possible with other diasporas. In contrast, Brubaker's (2005) alternative criterion of 'dispersion', 'homeland orientation', and 'boundary-maintenance' as signifiers of a diasporic group prove more analogous with the case of the Scottish diaspora. However, his 
claims regarding conceptualising membership of a diasporic group as "an idiom, a stance, a claim" (ibid: 12) equally emphasises the importance of self-identification by each individual in to consider themselves a member of a given diaspora, thus avoiding reification of a diasporic group which does not exist in the perceptions of its supposed members. Nonetheless, the widespread acceptance of the existence of a 'Scottish' national identity in the perceptions of individuals living within and outwith Scotland underlines the possibility of identifying a distinctly 'Scottish' diaspora, even if the pursuit of a homogenous 'Scottish identity' is a futile one given the regional, ethnic, religious, socio-economic and political divisions which exist within Scotland as a nation (Bairner, 2001; McCrone, 1992; Pittock, 2008).

The majority of extensive studies of the Scottish diaspora have focused particularly on Scottish emigrants in distant geographical locations throughout the world, such as North America, Australasia, the Caribbean and the Asian sub-continent (Devine, 1992, 2011; McCarthy, 2007a; Sim, 2011a). These works have highlighted the significant role Scots played in the expansion and maintenance of the British Empire during the Victorian era, with Scotland thriving as junior, but important, partners within the Empire (Devine, 1999; Harvie, 1998: Maclean, 2000; Mitchison, 1970). This status afforded Scots opportunities for selfadvancement both at home and overseas. In contrast, other studies of the Scottish diaspora have also highlighted that certain Scots were impelled 
to migrate due to developments such as the 'Highland Clearances' of the $18^{\text {th }}$ century, which resulted in a number of Scottish 'crofters' from rural areas being forced to seek employment in the rapidly urbanising Scottish cities or to settle in overseas locations such as North America (Jarvie, 1991; Devine, 2011). Regardless of the nature of the motivations for the Scottish diaspora to leave their home, both of these developments resulted in a significant increase in the number of Scots migrating to locations throughout the world, and thus the opportunity to spread Scottish cultural practices to other international settings. This resulted in the establishment of a number of Scottish cultural associations in areas with significant Scottish migrant populations, with a number of Scottish and Highland societies, Burns clubs and Masonic lodges founded in overseas locations during this period (Devine, 2011; McCarthy, 2007a). This institutionalised form of cultural association with their homeland therefore indicates that historically the Scottish diaspora in overseas locations adopted similar strategies to other diasporic groups in similar situations (Darby, 2009; Devine, 2011). However, it is important to note that the contrasting historical periods of Scottish emigration, the varying geographic locations and differing motivations for emigrants leaving Scotland ensured that this was not necessarily a uniform practice for all members of the Scottish diaspora (Devine, 2011; Jarvie, 1991, 2000, 2005).

Sport, Scottish Identity and the Scottish Diaspora 
In order to turn our attention to the importance of sport for the Scottish diaspora, it is important to firstly outline the relationship between sport and Scottish identity. For Scots, the existence of international sporting fixtures or events involving independent Scottish teams or individuals offers Scots the opportunity to maintain a sense of allegiance with their contemporaries, whilst also distinguishing themselves from other nationalities both within and outwith the UK (Bairner, 1994, 2001; Jarvie and Walker, 1994; Duke and Crolley, 1996; Moorhouse, 1987). Such arguments often invoke Anderson's (1991) conceptualisation of the nation as an 'imagined community', with Bairner (2001) arguing that sport offers the opportunity to give both physical form and voice to an otherwise abstract notion of a national identity, thus bringing the 'imagined community' of a given nation to life. Despite their geographical displacement, the Scottish diaspora can therefore participate in this 'imagined community' simultaneously with their contemporaries in Scotland. This can be achieved by viewing televised coverage of sporting events either individually or collectively with fellow Scots migrants, or through the consumption of mediated information on Scottish sport to maintain an active interest in Scottish sporting culture. However, it is again important to acknowledge that any notion that a singular Scottish identity is expressed through engagement with Scottish sporting culture is undermined by the same sociocultural and religious divides highlighted in the previous section; indeed, many have argued that sport acts as a major source of division with 


\title{
Scottish society (see Bradley, 1995, 2002, 2006; Dimeo and Finn, 2001; Finn, 1991a, 1991b; Horne, 1995).
}

\begin{abstract}
Although sport has the potential to play an important part in the lives of the Scottish diaspora in terms of maintaining a cultural association with Scotland, academic study of this specific topic is relatively scarce in comparison to other diasporic groups. Nonetheless, Grant Jarvie's $(1991,2000,2005)$ analyses of the historic diffusion of the Highland Games in North America provides a detailed account of the use of these events by Scottish migrants as a means of easing their transition into their new surroundings. For Jarvie, the establishment of the Highland Societies which organised these Highland Games events provided an opportunity to maintain a number of customs and cultural practices from Scotland, with an emphasis placed on Highland culture due to the prevalence of migrants from these regions due to the "Highland Clearances'. He also reflects upon the recent resurgence in the popularity of the Highland Games in North America for Americans and Canadians with Scottish heritage, whether recent or distant in their ancestry. Jarvie (2005) argues that the modern North American Highland Games have retained a romantic and mythologising view of the 'authentic' traditions and symbolism of Highland and Scottish culture which is significantly detached from the reality of contemporary life in Scotland, echoing debates regarding the 'invented traditions' of Scottish culture which emanate from modernist perspectives on the nature of nationalist sentiments (Hobsbawm 1983; McCrone 1992; Trevor-Roper 1983).
\end{abstract}


Nonetheless, Jarvie contends that attendance at Highland Games events and membership of Scottish or Highland societies offers the Scottish diaspora in North America the opportunity to engage with Scottish culture and heritage, whether valid or not, generating 'social capital' through their identification with their Scottish ancestry.

Extensive work on the role of sport for the Scottish diaspora has also been conducted by Richard Giulianotti and Roland Robertson, focusing again on the context of North America but instead scrutinising the role of football supporters' clubs for Rangers and Celtic, the two most popular football clubs in Scotland (Giulianotti, 2005; Giulianotti and Robertson, 2006, 2007). Giulianotti's initial study in 2005 analysed the extent to which these supporters' clubs afforded their members the opportunity to recreate sporting cultures from Scotland, thus maintaining a sense of Scottish identity in their new setting. He argues that active participation in these clubs creates opportunities for 'phatic communication' and 'vernacularisation of voice', whereby members can recreate 'Scottish' forms of accent, speech, debate and song associated with Scottish football culture, or, more specifically, 'Old Firm' football culture with its associated ethno-religious divides. Giulianotti and Robertson's $(2006,2007)$ collaborative work draws upon data from the same interviews as the 2005 study, this time deploying the concept of 'glocalisation' to critique the extent to which these supporters' clubs are able to recreate Scottish sporting culture in the North American context. Their studies identify a number of challenges faced by the Scottish 
diaspora in recreating Scottish culture and/or maintaining a Scottish identity in their new setting, due to a selective approach to identification with Scottish cultural identity by Scottish migrants, the existence of 'banal relativization' of Scottish culture in comparison to the prevalent cultural forms in North America, and the growing availability of alternative cultural associations which compete with those relating to Scottish culture. These studies therefore identify a number of issues for the future maintenance of 'glocal' Scottish identities within later generations of the Scottish diaspora, with the impact of mediated coverage of North American sports prevailing over Scottish football in the eyes of second and third generation members of the diaspora, negating the possibility to maintain interest in Scottish football and sporting culture in general (Giulianotti and Robertson, 2006, 2007).

\section{The Scottish Diaspora in England}

Although the majority of studies of the Scottish diaspora have focused on locations outside of the UK, a growing number of studies have also considered the migration of Scots to England (e.g. McCarthy 2005, 2007b; Leith and Sim, 2012; Sim, 2011a). It has been argued that Scots living in England have often been overlooked as a legitimate form of diaspora given that on a nation-state level this can be classified as a form of 'internal migration' (McCarthy, 2005, 2007b). The relationship between Scotland and England as part of the United Kingdom is complex. In his analysis of the realpolitik of island union, Miller (2005) highlights 
imbalances in the size of the nations' relative populations and the asymmetric migration patterns which result in a net flow of Scots to England as amongst the many causes of tension between two nations. The imbalance between Scotland and England is also reflected in the political economy of the United Kingdom, with England holding a historically dominant position in terms of relative distribution of wealth, resources and political control. Miller (2005) argues that this has in turn led to the development of asymmetric national identities in line with actual and perceived differences between the two nations on a social, political and cultural level, with England often presented as an 'other' to Scotland despite abundant evidence to the contrary. However, given that many Scots and non-Scots would argue that there a clear notion of a Scottish nation exists, even if not on the basis of sovereign statehood, it can be argued that Scots moving to England do represent a significant form of migration in terms of scale and dislocation, both geographic and cultural. Furthermore, the forthcoming referendum on Scottish independence in October 2014 may result in the establishment of a sovereign Scottish nation-state, potentially removing any doubts that Scots in England do indeed constituent a diasporic group.

In terms of maintaining cultural associations with their Scottish homeland, Scots living in England have been argued to adopt a contrasting approach in comparison to the Scottish diaspora situated outside the UK. Academic discussions of the lifestyles of Scots living in England have suggested that these individuals are less likely to engage in 
explicit and institutionalised forms of cultural association such as Scottish societies and clubs, instead preferring to adopt an implicit, social-mental Scottish identity (McCarthy, 2005, 2007a, 2007b; Sim, 2011a). A number of Scottish cultural organisations remain in England, with the majority of these organisations taking the form of 'Scottish' or ‘Caledonian' societies, Scottish country dancing societies, and Burns clubs. According to the Royal Scottish Country Dance Society website, there are currently 68 Scottish country dancing societies located in England (www.rscds.org), whilst lists of Scottish and Caledonian societies elsewhere identifying 28 active societies in England (www.rampantscotland.com); these lists also contain omissions of numerous other Scottish societies in England. However, the membership levels of these organisations has declined significantly in comparison to those overseas or from other comparable diasporic groups in England, such as the Irish (McCarthy, 2007b; Sim, 2011a, 2011b). For example, on the few occasions where the official websites provided estimated membership figures, the number of members ranged from approximations of 50 to 210 members (www.bedscotsoc.org.uk; www.chesterfieldcaledonians.moonfruit.com;

www.exetercaledoniansociety.co.uk; www.harrowscottish.org.uk; www.wdsa.co.uk). Given the estimated figure of 800,000 Scots living in England (Ancien, Boyle and Kitchin, 2009; Sim, 2011a), it is clear that membership of such organisations plays a part in the lives of only a small minority of the Scottish diaspora in England. 
McCarthy (2005) argues that these contrasting strategies are a result of the cultural similarities between Scotland and England which facilitate the assimilation of Scots into their new surroundings, as well as the contrasting historical eras in which the forms of migration took place. Instead, Scots in England tend to rely on the development of smaller personal networks with fellow Scots in England as well as more frequent trips 'home' to maintain their association with Scotland, whilst the existence and maintenance of a Scottish accent continues to act as a natural demarcation of their Scottish identity (McCarthy, 2005).

\section{Sport and the Scottish Diaspora in England}

Given this perception of contrasting strategies used by Scots in England compared to Scots overseas, it is apt to now consider the extent to which this contrast is evident in the sporting domain. Whilst the studies of Jarvie, Giulianotti and Robertson outlined above have made an undoubtedly significant contribution to the understanding of the role of sport for the Scottish diaspora, their shared focus on a North American context highlights the necessity for further research which focuses specifically on the topic of sport in other locations containing a significant number of Scottish migrants. Furthermore, such research can also shed light into the lifestyles of the significant proportion of the Scottish diaspora who have little or no interest in either the Highland Games or the 'Old Firm' football teams. Given that the majority of Scots living outside of Scotland reside in England, it seems appropriate that 
research in this specific setting will help to further expand our understanding of this topic.

Some headway has been made in tackling this issue by the studies of McCarthy (2005) and Leith and Sim (2012), which both make passing reference to the importance of sport in their studies of the Scottish diaspora in England. Although McCarthy's study concentrated on ideas of national identity and the Scottish diaspora in a wider sense, she highlights the role sport can play in distinguishing Scots from the English during sporting competitions. In particular, she discusses the contention that Scots are unwilling to support the English football team, highlighting the issues this has raised for participants in her study during their experiences living in England. Leith and Sim's (2012) study echoes the arguments of Giulianotti and Robertson (2006, 2007) regarding the challenges of engaging second and third generation members of the Scottish diaspora with Scottish sporting culture. Their interviewees highlighted that the existence of separate Scottish and English teams in international football led to issues regarding which national teams their children would support, with the allure of the more successful 'host' nation of England often attracting second generation members despite their parents' support for Scotland. Leith and Sim (2012) argue that the lack of engagement with Scottish culture can be attributed to a lack of a Scottish 'symbolic ethnicity' for second generation Scots living in England compared with those situated further afield. Furthermore, given that England has been frequently argued to act as the 
predominant sporting rivals for supporters of Scottish international teams (Bairner, 1994, 2001; Blain and Boyle, 1994; Kelly, 2007; Moorhouse, 1984, 1986, 1987, 1994, 1995; Whigham, in press), the potentially divisive nature of sporting competition in the relationship between the 'host' and 'home' countries found by McCarthy (2005) and Leith and Sim (2012) is unsurprising).

Although the findings of these studies have began to identify some nuances of the relationship between sport and the Scottish diaspora in England, the placing of sport as the primary focus of the current research aims to flesh out the initial arguments made by these authors in their more broadly-focused analyses. Attention will now turn to outlining the methods adopted in the current study in its attempts to further understand the manner in which Scots living in England use sport to link to their Scottish 'home'.

\section{Methodology}

The interviews discussed in this study were conducted in 2011, with 13 interviewees identified through the use of a theoretical snowball sampling strategy. In order to participate in the study, interviewees had to have been born in Scotland and to have current residence in England. Initial contact was made with 5 personal acquaintances in various geographic locations in the South East and East Midlands regions who met these criteria. The 8 additional participants were identified through 
personal networks of the initial participants, with attempts made to provide an element of age and gender representation across the interviewee sample. This sampling strategy contrasts significantly with the approaches adopted by other studies of the Scottish diaspora in England which opted to recruit participants by accessing members of formal Scottish social and cultural organisations in a specific geographic locale (McCarthy, 2005, 2007a, 2007b; Sim, 2011a, 2011b; Leith and Sim, 2012). Such an approach facilitated the opportunity to examine the experiences of members of the Scottish diaspora who do not necessarily actively maintain a cultural attachment with Scotland in an institutionalised form, thus complimenting the findings of the existing literature on the Scottish diaspora in England.

However, it is important to acknowledge that this sampling method precludes the opportunity to provide a robust comparison of the contrasting experiences of Scots who do and do not engage with Scottish cultural organisations in England, an area which merits further consideration in the future. Furthermore, any attempts to claim 'theoretical saturation' is clearly outwith the capabilities of the current study given its relatively ideographic nature. The starting point for the current analysis is that any search for generalisability from this sample to the wider Scottish diasporic population in England is ultimately futile given the subjective, unique and shifting nature of an individual's sense of self, the contrasting experiences of Scots living in contrasting locations in England, and the obvious lack of homogeneity within a 
diasporic group in the region of 800,000 people (Ancien, Boyle and Kitchin, 2009; Sim, 2011a). Instead, it is of more analytical interest for the current study to produce rich data which emphasises the nuanced nature of each respondents' opinions and experiences, thus allowing the opportunity to explore what is important to the current interviewees and their personal 'ontological narrative'. Such a strategy therefore facilitates a more thorough reflection of the experience of each individual in light of the findings of studies of the other diasporic groups in England and elsewhere, allowing the opportunity to reflect upon the similarities and dissimilarities in the experiences of this study's participants in comparison to those in alternative locations and/or diasporic groups.

In order to generate the rich data required for this approach, this study adopted the 'life story' approach advocated by Atkinson (1998) within its semi-structured interviews, with interviews ranging in length from 35 to 135 minutes. Similar approaches have been adopted in other studies of the Scottish diaspora (McCarthy, 2005, 2007a; Sim, 2011a, 2011b, 2012), placing emphasis on exploring the development of each interviewee's sense of self across time and space. This allowed for an analysis of the contrasting ways in which each individual had experienced migration to England, as well as facilitating the opportunity to analyse whether their identification with their Scottish birthplace had shifted over time. Such an approach also allowed for a consideration of the impact of each individual's personal circumstances on their lifestyles 
and attitudes, given that the discussions were framed in relation to the age, gender, social class, employment, and political beliefs of each participant, all of which have potential implications for the nature of their engagement with their Scottish birthplace. All 13 interviews were recorded electronically and transcribed verbatim. The transcripts were then analysed using a thematic narrative analysis strategy, with emphasis placed on identifying themes which linked to their 'ontological narratives' of their experiences as a member of the Scottish diaspora, and the various sources of 'public narratives' which has influenced their identification (or non-identification) with their Scottish birthplace (Somers, 1994; Somers and Gibson, 1994). Furthermore, particular attention was paid to the role of sport as a means of maintaining cultural and emotional attachment to Scotland. Each interviewee has been given a pseudonym to protect their anonymity in the forthcoming discussion of the various themes which emerged as a result of this analysis.

\section{Discussion}

Reflecting upon the central outcomes of the interviewees, it is possible to organise the emergent themes into two sections for the purposes of this discussion. The first section of this analysis will concentrate on the cultural similarities and differences between Scotland and England as perceived by the interviewees, and the positioning of England as a cultural and political 'other' by the Scottish diaspora. Attention then turns to the strategies adopted by the Scottish diaspora in 
England to maintain links with their Scottish birthplace in the second section, before specifically considering the importance of sport as a means of maintaining a cultural attachment to Scotland in the third section.

Scottish and English Culture - Perceptions, Comparisons and Contrasts

In order to gain a fuller appreciation of the strategies used by Scottish migrants in England, consideration of the interviewee's perceptions of cultural, social and political differences between Scotland and England acts as an important first stage in contextualising the experiences of the Scottish diaspora in this particular setting. This is particularly crucial in this case in order to avoid exaggeration of the points of difference between the two nations. When prompted to consider the comparisons and contrasts between Scotland, England, and their respective populations, the majority of interviewees emphasised that they felt that overall there were many similarities and few major differences:

\footnotetext{
I think that Scottish people would kind of a little bit be clumped in with white people in London. I suppose that's kind of how I think of it myself, because you have the same sort of cultural values... I would think of Polish people and Eastern European people as white people, but then they speak different languages and have a different culture of their own. Whereas with
} 
Scottish people and English people, you speak English, and there's a very similar education system and very similar upbringing. (Morag)

You couldn't put a fag paper in between what we're like as people, we're very similar. (Paul)

Only two respondents felt more strongly about the extent of difference between the two countries, arguing that there are significant contrasts to be drawn. Nonetheless, it is possible to begin to identify certain areas of divergence between Scotland and England which were viewed by a number of interviewees as important factors in understanding the relationship between the two countries, echoing many of the arguments of Miller (2005). One such contrast which was cited by the majority of respondents was the view that England was financially richer than their neighbours in Scotland:

I mean, y'know, to me, there strikes me as being a lot... quite a lot of differences. Um... there's huge financial differences. Prices of property, stuff like that. I think that the opportunities are not so abundant up there. (Richard)

I think in Scotland they feel a bit... a lot of people say... well, probably before even you can... well, maybe you're interested in, was in the 1930s when there were people who didnae have any employment, and they couldn't get food, or get money or anything. I think they had it better down in England than they had it up in Scotland. (Alison) 
This was seen to manifest itself in the belief that this was linked to a better lifestyle for people living in England, despite some acknowledgement of the additional cost of living associated with this higher standard of living.

The differences in wealth identified between Scotland and England were also linked with a perceived difference in the prevailing political and social opinion found in each country, with England presented as a political 'other' by some participants. With frequent references to the socialist leanings of Scottish political opinion, this was juxtaposed against an English political leaning towards more conservative attitudes:

\footnotetext{
Em... I do think there is social and political differences. I think Scotland is much more socialist and left-wing, and I think England tends to be a bit more conservative and right-wing. Having said that, that's only what I've kind of experienced of being, like, in southern, south-east England where it's quite affluent. (Morag) .
}

In that sense, you're thinking this is a more conservative or centrist country than Scotland, but again you've got to be careful that that's not investing qualities in Scotland that you would like Scotland to have, and it goes back to myths about democracy, and so on. And, y'know, it may well be that if Scotland got its independence, it would have a permanent centre-right majority as well for all I know, but I think up to now you've got a sense that there's a little bit more commitment to some kind of egalitarianism. (Bob) 
The perceived differences in wealth and lifestyle between the two countries were also deemed to impact upon certain personal characteristics and traits of the general English persona, such as a sense of superiority and entitlement. However, not all participants opted to position English cultural, political and social attitudes in such a generalised manner, and many attempted to outline that 'England' was not a homogenous entity in their perceptions. For example, a common related argument emphasised that there was a significant divide within England which in fact lead to certain commonalities with Scotland in relation to notions of a north-south divide within the UK:

I actually think the traits I would describe to Scottish people would apply to people like from Newcastle and Sunderland and that. (Bert)

I grew up in Carlisle, in the north of England, and I think the people in the north of England have a lot more in common with the people of Scotland than they have with people in the south of England, bizarrely, although would cheer for England when it comes to sport. But growing up in Carlisle, and I've got lots of friends from places like Burnley and Hull and y'know, those people have a lot more in common with most Scots than they would with people from the Home Counties down here, or people in Oxford. (Scott)

Another interesting difference identified by a selection of participants was the opinion that Scots were more likely to engage with predominant notions of Scottish identity. The reasons behind this contrast were argued to lie in the view that Scottish nationality and 
identity were more fully developed, and based upon more tangible and coherent foundations in comparison to English or British national identification:

I think Scottish people are more patriotic for their country, I think. Whereas English people think we're united... UK or Great Britain, whereas Scottish people, we're just Scottish. (Mark)

The thing I like about Scottishness, y'know, is being able to identify myself with Scotland... it gives me a sort of coherent, a stronger coherent identity with a specific place. If I was a... I dunno... from Cheshire, or some anonymous county... and aye, if you live in Derbyshire, maybe you feel... you might not have a strong affinity to a particular locality, but maybe you would. I dunno. But I feel that a Scottish identity gives you a more coherent identity than you could have, if, y'know, than if you were English, y'know. (Harry)

Discussion of the differences in lifestyle and culture also resulted in the identification of less positive evaluations of Scotland in relation to England. Again, drawing upon the discussion of characteristics of Scottish identity, particular differences were found in relation to poor diet and higher alcohol consumption in Scotland. Discussion of the social environments in which drinking took place found less consensus, with some respondents arguing that there is a stronger pub culture in England whereas others argued the same for Scotland. Other cultural differences were proposed in relation to an increased market culture in England, differences in traditional forms of music and art, and the increased 
engagement with hobbies and pastimes by individuals living in England. These arguments lead nicely onto a consideration of the differences found in relation to the cultural interest which will be of specific focus in the discussion which ensues regarding the role of sport for the Scottish diaspora in England.

\section{Scottish Culture, Sport and Internal Migration}

Having summarised the predominant perceived cultural, social and political differences between Scotland and England, attention now turns to gaining an appreciation of the manner in which the Scottish diaspora in England may maintain a cultural attachment with Scotland. In this regard, a notable phenomenon cited by a number of respondents was as increased interest in Scottish affairs and culture after leaving Scotland, with consumption of Scottish print and online media content identified by a number of interviewees as a common means of maintaining a cultural attachment with home:

\footnotetext{
I read the Scottish news on the BBC after the headlines. So I never look at the Oxford local news on the BBC website even though I have it, but I would... I look at the Scottish news almost every single day. And I think it does... I don't know if that's to do with being Scottish or... and it's not to do with homesickness because I've lived here for 11 years. But I am interested in what's going on in Scotland. (Michael)
}

URL: http://mc.manuscriptcentral.com/rlst 
Particular reference was also made to reading books about Scotland and its history:

I'm sure its homesickness in the first instance. I mean, you're away from home. How do you get contact with it... em... of a really personal nature? For me, it was reading about it. And increasingly in Belfast, whenever I went home I was buying cassettes of Scottish folk music... I wouldn't say it's all exiles, it's different. I mean if you're doing a $\mathrm{PhD}$ and you're spending a lot of time in a university library or a bookshop, you've got access to that kind of thing. I mean, other people though it might be reading The Scotsman or The Herald or The Dundee Courier on a daily basis, which I tend not to do. (Bob)

This was argued to be fairly typical behaviour for ex-pats and exiles of all countries, and was frequently explained in relation to personal feelings of dislocation and detachment from Scotland:

There's undoubtedly been, from a very young age, a desire to be part of something Scottish. And following the football team and the rugby team is a big part of that. Reading stuff and reading books has always been a part of it as well. And I guess it's typical of ex-pats, wherever they are, you have that sense of something missing that you go into it in a way that you might not have otherwise. Em... but yeah, I'm absolutely sure that I've been dislocated from it from the moment I moved south in 1972. (Scott)

As outlined above, the cultural practices adopted by my interviewees tended to be individual in their nature, with no participants stating that they actively participated in communal social and cultural 
organisations to maintain a bond with their Scottish birthplace. However, sport was argued to be the one domain in which such behaviour was more widespread:

We used to go and watch the games... there's a couple of pubs in London, there's the William Wallace and the Rob Roy. So we used to go through on the bus because it was the only place where you could actually see the games live at the time, before Sky started showing all the Scotland games... I mean, there really was no other option to see the game if you couldn't go up to Scotland to see the game or if it was an away fixture. (Scott)

In terms of maintaining links to Scotland, the participants expressed an interest in team sports such as football and rugby predominantly, followed by athletics, tennis and golf. One aspect of the relationship between sport and Scottish identity discussed was the emphasis on the importance of separate Scottish representative teams in international sporting competition for distinguishing Scotland as an independent entity, as argued by Bairner (1994; 2001). Given that the opportunities to identify Scotland as a distinct nation on the global stage are limited due to its status as a 'submerged nation', the presence of Scottish teams in specific sporting contexts offers the change to promote an element of independence for the Scottish nation:

I guess more that there is a very independent... you know, a Scotland team rather than a British team that puts it very much at the forefront... it is I think one of the only relatively few times when Scotland is independent from the rest of the country and the UK. (Sandra) 
I mean... it would have been a shame I guess like growing up if the Scottish football team didn't exist. Y'know, with this whole Olympic sort of debate now, if it had been Team Britain. Because I remember watching Britain actually winning a hockey gold medal, and I thought that was quite cool. But it's just not the same. (Bert)

Therefore, the ability of sport to generate distinctive ideas of the ScottishEngland divide undermined the common bonds between the two countries, even for those who argued that regional and class-based similarities exist:

\begin{abstract}
So... so, I think it's interesting how in lots of ways growing I felt that the north of England has a lot more in common with Scotland. I think obviously when it comes to sport that identity splits completely. (Scott)
\end{abstract}

\begin{abstract}
Although the majority of interviewees discussed their interest in Scottish international and club sport as a marker of their cultural attachment with Scotland, there was no evidence of any interviewees participating in more formalised sporting or social organisations which offered the opportunity to specifically engage with other Scots in England. Some interviewees demonstrated an awareness of the existence of such organisations or made alternative attempts to congregate with fellow Scots to watch Scottish sport at pubs or at home as noted above; however, membership in Scottish sporting, cultural and social organisations did not play a part in the lifestyles of this study's participants. This contrasts directly with the findings of Giulianotti (2005), Giulianotti and Robertson (2006,
\end{abstract}


2007), McCarthy (2005; 2007a), and Leith and Sim (2012); however, given that their research used formal organisations such as these as a means of recruiting participants for their analyses, this is unsurprising.

Another contrast with the findings of previous studies of this group lies in the omission of the Highland Games in discussion when considering the role of sport for the Scottish diaspora in England, given the emphasis placed upon such events in Jarvie's (1991, 2000, 2005) work on the spread of the Games in North America. Indeed only one participant mentioned the Highland Games in passing:

Highland Games to me are, like, Scottish sports. Football is just a national sport, it's worldwide, isn't it? Y'know, there's no really any Scottish sports that shine out, within the country or anything like that. I mean, you never get to see it unless you're up in the north of Scotland somewhere. (Brian)

The lack of reference to the Highland Games appeared to be symptomatic of a relative disinterest in such events as a mark of Scottish heritage for Scots in England compared to those in North America. This difference could potentially be explained by the fact that the sample of interviewees was skewed towards those from the Central Belt who may not have had as much direct involvement and exposure to Highland Games events. Furthermore, in a more general, it could also be argued that Scots living in England who retain a strong interest in Highland Games events could attend such events with much more ease than their 
counterparts in more distant locations. The relative unpopularity of sports with distinct Scottish origins for members of the Scottish diaspora in England lies in direct contrast with migrants from Ireland, for whom sports such as hurling and Gaelic football have continued to act as an important leisure activity in their new setting (Darby, 2009; Darby and Hassan, 2008). The failure to establish a strong attachment with Scottish sports such as the Highland Games and shinty has been attributed to the lack of a Scottish equivalent to the Gaelic Athletic Association which has promoted participation in Irish sports effectively (Bradley, 1998). The only exception to this pattern is golf, although the extent to which golf is an indigenous Scottish sport is highly debatable (Gillmeister, 2002). The establishment of sports clubs with Scottish links is evident in certain places, with London possessing a number of amateur football teams participating in local leagues, as well as the example of London Scottish Football Club who compete in the second tier of the English rugby union league system. However, the number of Scottish sporting organisations in England is negligible in comparison with the Irish diaspora (Darby and Hassan, 2008), despite possessing a similar number of migrants in England to their Irish counterparts.

An additional explanation provided by the interviewees for their lack of interest in participating in Scottish sporting organisations in England was the ease of access to mediated coverage of Scottish international and club sport, thus negating the requirement for collective organisations which provide such access in alternative settings for the 
Scottish diaspora. It is now possible for Scots in England to follow Scottish international teams, club teams and individual athletes from the comfort and privacy of their own home at a relatively low cost, given that their status as 'internal migrants' within the UK allows them access to the same broadcasters as their compatriots in Scotland, such as the BBC, ITV, Sky, ESPN and BT Sport:

\footnotetext{
I wouldn't say I'm more interested in Scottish football because I don't get to see enough of it, but I got Sky TV a few years ago and I was... eh, 18 months ago. And it's fantastic because you can watch Sportscene or whatever on BBC One, and sometimes they've got live games on BBC Alba. (Michael)

It was mostly the Hearts website, and then you listened to the radio. You could listen to the radio, y'know, streamed through the website. So that would be... I listen to a lot of games live online. The cup final as well, I listened to that online. (Mark)
}

Scots living in England are therefore able to participate as members of the Scottish sporting 'imagined community' (Bairner, 2001) from the comfort of their armchair if they choose. This contrasts significantly with the contexts of Scots living in more distant geographic locations where access to mediated sports coverage is more limited, and is often dependent upon more costly subscriptions to specialised satellite providers given the marginalised status of Scottish sport within the global sports media market. Accessing coverage of Scottish sport therefore often necessitates attendance at public venues such as sports bars and clubs, or joining the 
formal sporting organisations discussed by Giulianotti and Robertson (2006, 2007). This means that Scots in more distant locations may be more likely to meet with fellow Scots communally in order to access Scottish sport, thus developing new personal and social contacts with fellow Scots through a shared interest in Scottish sport:

In Australia, you bumped into people when you went to watch the football. You always bumped into, y'know, someone who supported their team. Or when you were in Australia, you could watch Hearts on telly, for example, and you'd bump into people from Edinburgh and you'd keep in touch with them. So it was just sort of randomly meeting people, and then you'd keep in touch with them, eh? (Mark)

However, the impact of recent developments in live internet-based streaming technology for sports fixtures and events may yet reduce the necessity for Scots in overseas settings to congregate in this manner. These findings regarding the impact of developments in media and electronic communication chime with the arguments of Finch, Latorre and Andrew (2010), who argue that the British diaspora are increasingly relying upon social networking websites and electronic media consumption as a means of maintaining personal, social and cultural attachments with their home.

This dependency upon everyday individual activities to maintain a bond with their Scottish home can be viewed as partially echoing some of the arguments in Billig's (1995) 'banal nationalism' thesis. In particular, 
Billig emphasises the routine flagging of the nation in society through the production and consumption practices of the mass media. He argues this is particularly pronounced in the case of sport, highlighting the emphasis given to national teams and individuals and the feeling of shared experience fostered through media consumption. Although Scots living in England retain access to the same print and broadcasting media forms as their counterparts in Scotland, the existence of bespoke Scottish editions of the tabloid and broadsheet newspapers and the regional variations in the content of BBC Scotland and STV programming results in a significant contrast between the Scottish and English context. Scots living in England therefore need to actively pursue coverage of Scottish sport in print and electronic media by drawing upon Scottish media sources, as there is only limited coverage offered to Scottish sport in the mainstream media sources in England. This existence of such behaviour for Scots living in England therefore adds credence to the arguments of Giulianotti and Robertson $(2006,2007)$ regarding the prevalence of 'banal relativization' in relation to sport's role for members of the Scottish diaspora.

\section{Conclusions - Geographic Proximity, Cultural Proximity and} Internal Migration

In order to begin drawing some initial conclusions regarding the distinctive manner in which Scots living in England, a brief comparison between this diasporic group with their Scottish counterparts in more 
distant locations (such as North America and Australasia) or with similar diasporic groups in England (such as the Irish diaspora) can begin to coax out some of the central points of difference in the role of sport as a means of cultural attachment with a migrant's birthplace.

The first such point of difference relates to the geographic proximity of Scotland to England. Given the close proximity of England to Scotland, it remains the most common destination for Scots migrants who are pursuing career advancement or relocation. Although Scottish 'internal migrants' in England face significant challenges in maintaining a 'Scottish' cultural identity as do Scots in locations further afield, the geographic proximity of Scotland to England facilitates more frequent returns to Scotland and an increased possibility of maintaining strong links with the family and social networks which are often intertwined with attachments to Scottish sport. For Scots in England, maintenance of an identification with their Scottish homeland often required alternative and conscious means compared to those still in Scotland. However, the means by which Scots in England maintain a cultural attachment with Scotland differs from those in settings with less geographic proximity to Scotland. Echoing the findings of McCarthy (2005), the current research found no evidence of engagement with Scottish cultural organisations which promoted engagement with Scottish sport or wider culture, contrasting with the findings of Jarvie (1991, 2000, 2005), Giulianotti (2005), and Giulianotti and Robertson $(2006,2007)$. However this is an issue which merits further study given the relatively ideographic nature of 
this study, and its contrasting sampling strategy when compared to past studies of the Scottish diaspora in England which have explicitly studied the members of these organisations (McCarthy, 2005, 2007a, 2007b; Sim, 2011a, 2011b; Leith and Sim, 2012). Future studies in this area are therefore required to consider the impact of geographic location as well as the comparative demographics of Scottish migrants who do and do not participate in such organisations.

A second point of difference in the role of sport for Scottish migrants relates to the cultural proximity of an English context vis-a-vis the common cultural forms and practices found in Scotland, with the comparisons drawn between the practices of Scottish and Irish diasporic groups in England proving instructive here. As we have seen, the interviewees perceived only minor cultural differences between Scotland and England in both a sporting and wider cultural sense, as would be expected for 'internal migrants' moving to new locations within a nationstate. Furthermore, near-identical access to mediated coverage of Scottish sport within the UK broadcasting system negated the need to go to great lengths to engage with Scottish sport. It can therefore be argued that a strong cultural proximity exists in the contexts of Scotland and England. However, for Irish migrants it can be argued that the cultural proximity of their new setting in England is lower than that of Scottish migrants, given the differences in predominant religious and sporting practices in comparison to their Irish birthplace (Darby, 2009; Darby and Hassan, 2008), further pronounced for the minority of Irish migrants for 
whom Irish Gaelic is their first language. The more widespread emergence of Irish cultural and sporting organisations in the English context can therefore be argued to be the result of a more explicit attempt to recreate the cultural practices of their Irish birthplace. In contrast, such overt attempts are less frequent for Scots migrants due to the cultural similarities between England and Scotland.

With its specific focus on this specific group of Scottish 'internal migrants', this article has been able to explore the role of Scottish sport and culture in the everyday lives of Scots in this particular context in greater depth than previous studies (McCarthy, 2005; Leith and Sim, 2012). However, it would be remiss in a study of Scottish 'internal migrants' in England to fail to discuss the possible implications of the forthcoming Scottish independence referendum in September 2014 within these final thoughts. The political 'othering' of England evident in the current study has potential ramifications for the constitutional future of Scotland and the United Kingdom, as campaigners on opposite of the debate attempt to either emphasise or de-emphasise the political contrasts between the two countries in order to advance the case for Scottish independence or continued political union. The consequences of a 'Yes' vote will ensure that Scotland will make a transition from a 'submerged nation' to a fully-fledged 'nation-state', significantly altering the status of the Scottish diaspora in England. The theoretical shift from the status of an 'internal migrant' to the same status of other migrant groups in England is likely to have little impact upon the daily practices 
of Scots in England due to the continued high levels of geographic and cultural proximity between the two countries. However, the manner in which such Scots maintain a cultural and political attachment with their birthplace is more likely to be altered given that the vast majority will be unable to personally vote on the constitutional future of Scotland, despite the implications this may have for their own citizenship. The possibility of the Scottish electorate opting for independence highlights that the political, economic, cultural and social dynamics within the British Isles could potentially be reformulated; perhaps future academic analysis of the Scottish diaspora living in within the British Isles will also require such a reconsideration.

\section{References}

Ancien, D., Boyle, M., \& Kitchin, R. (2009). The Scottish diaspora and diaspora strategy: Insight and lesson from Ireland. National University of Ireland: Scottish Government Social Research.

Anderson, B. (1991). Imagined communities: Reflections on the origins and spread of nationalism (2nd ed.). London: Verso.

Atkinson, R. (1998). The life story interview. Thousand Oaks, CA: Sage. 
Bairner, A. (1994). Football and the idea of Scotland. In G. Jarvie \& G. Walker (Eds.) Scottish sport in the making of the nation: Ninety minute patriots? (pp.926). Leicester: Leicester University Press.

Bairner, A. (2001). Sport, nationalism and globalization: European and North American perspectives. Albany, NY: State University of New York Press.

Billig, M. (1995). Banal nationalism. London: Sage.

Blain, N. \& Boyle, R. (1994) Battling along the boundaries: The marking of Scottish identity in sports journalism. In G. Jarvie \& G. Walker (eds) Scottish sport in the making of the nation: Ninety minute patriots? (pp. 125141). Leicester: Leicester University Press.

Bradley, J.M. (1995) Ethnic and religious identity in Scotland: politics, culture and football. Aldershot: Avebury.

Bradley, J. M. (1998). Sport, culture, politics and Scottish society: Irish immigrants and the Gaelic Athletic Association and culture. Edinburgh: John Donald Publishers Ltd. 
Bradley, J.M. (2002) The patriot game: football's famous 'Tartan Army'. International Review for the Sociology of Sport 37(2): 177-197. doi: $10.1177 / 1012690202037002004$.

Bradley, J.M. (2006) Sport and the contestation of ethnic identity: football and Irishness in Scotland. Journal of Ethnic and Migration Studies 32(7): 1189-1208. doi: $10.1080 / 13691830600821885$.

Braziel, J. E., \& Mannur, A. (2003). Theorizing diaspora: A reader. Oxford: Blackwell

Brubaker, R. (2005) The 'diaspora' diaspora, Ethnic and Racial

Studies, 28(1), 1-19. doi: 10.1080/0141987042000289997.

Burdsey, D. (2006). 'If I ever play football, Dad, can I play for England or India?’ British Asians, sport and diasporic national identities. Sociology, 40(1), 11-28. doi: 10.1177/0038038506058435

Carrington, B. (2010). Race, sport and politics: The sporting black diaspora. London: Sage. 


\section{Chesterfield and District Caledonian Association (n.d.) 'Welcome'. Retrieved from www.chesterfieldcaledonians.moonfruit.com.}

Cohen, R. (2008). Global diasporas: An introduction. Abingdon: Routledge

Darby, P. (2009). Gaelic games, nationalism and the Irish diaspora in the United States. Dublin: University College Dublin Press.

Darby, P., \& Hassan, D. (2008). Introduction: Locating sport in the study of the Irish diaspora. In P. Darby \& D. Hassan (Eds.), Emigrant players. Sport and the Irish diaspora. (pp. 1-14). London: Routledge.

Devine, T. M. (Ed.). (1992). Scottish emigration and Scottish society. Edinburgh: John Donald.

Devine, T. M. (1999). The Scottish nation: 1700-2000. London: Penguin.

Devine, T. M. (2011). To the ends of the earth: Scotland's global diaspora, 17502010. London: Penguin. 
Dimeo, P. \& Finn, G.P.T. (2001) Racism, national identity and Scottish football. In I. McDonald \& B. Carrington B (eds) 'Race’, sport and British society (pp. 29-48). London: Routledge.

Duke, V., \& Crolley, L. (1996). Football, nationality, and the state. Harlow: Longman.

Exeter and District Caledonian Society (n.d.) 'Contacts'. Retrieved from http://www.exetercaledoniansociety.co.uk/contacts.htm.

Fielding, T. (2012). Migration in Britain: Paradoxes of the present, prospects for the future. Cheltenham: Edward Elgar Publishing.

Finch, T., Latorre, M., \& Andrew, H. (2010). Global Brit: Making the most of the British diaspora. London: Institute for Public Policy Research.

Finn, G.P.T. (1991a) Racism, religion and social prejudice: Irish Catholic clubs, soccer and Scottish society - I the historical roots of prejudice. International Journal of the History of Sport 8(1): 72-95. doi: 10.1080/09523369108713746. 
Finn, G.P.T. (1991b) Racism, religion and social prejudice: Irish Catholic clubs, soccer and Scottish society - II social identities and conspiracy theories. International Journal of the History of Sport 8(3): 370-397. doi: 10.1080/09523369108713768.

Finney, N., \& Simpson, L. (2008). Internal migration and ethnic groups: evidence for Britain from the 2001 Census. Population, Space and Place, 14(2), 63-83. doi: $10.1002 / \mathrm{psp} .481$

Gillmeister, H. (2002). Golf on the Rhine: On the origins of golf, with sidelights on polo. The International Journal of the History of Sport, 19(1), 2-30. doi: $10.1080 / 714001691$.

Giulianotti, R. (2005). Towards a critical anthropology of voice: The politics and poets of popular culture, Scotland and football. Critique of Anthropology 25(4): 339-359. doi: 10.1177/0308275X05058654.

Giulianotti, R., \& Robertson, R. (2006). Glocalization, globalization and migration: The case of Scottish football supporters in North America. International Sociology, 21(2): 171-198. doi: 10.1177/0268580906061374. 
Giulianotti, R. \& Robertson, R. (2007). Forms of glocalization: Globalization and the migration strategies of Scottish football fans in North America. Sociology, 41(1): 133-152. doi: 10.1177/0038038507073044.

\section{Harrow and District Caledonian Society (n.d.) 'Home'. Retrieved from http://www.harrowscottish.org.uk.}

Harvie, C. (1998). Scotland and nationalism: Scottish society and politics 1707 to the present. London: Routledge.

Hobsbawm, E. (1983). Introduction: Inventing tradition. In E. Hobsbawm \& T. Ranger (Eds.) The invention of tradition. (pp. 1-14). Cambridge: Cambridge University Press.

Horne, J. (1995) Racism, sectarianism and football in Scotland. Scottish Affairs 12: 27-51.

Jarvie, G. (1991). Highland Games: The making of the myth. Edinburgh: Edinburgh University Press. 
Jarvie, G. (2000). Highland Games. In G. Jarvie \& J. Burnett (Eds.) Sport, Scotland and the Scots. (pp. 128-142). East Linton: Tuckwell.

\begin{abstract}
Jarvie, G. (2005). The North American Émigré, Highland Games, and social capital in international communities. In C. Ray (Ed.) Transatlantic Scots. (pp. 198-214). Tuscaloosa, AL: University of Alabama Press.
\end{abstract}

Jarvie, G., \& Walker, G. (1994). Ninety minute patriots? Scottish sport in the making of the nation. In G. Jarvie \& G. Walker (Eds.) Scottish sport in the making of the nation: Ninety minute patriots? (pp. 9-26). Leicester: Leicester University Press.

Kaufman, H. (2005). Jewish sports in the Diaspora, Yishuv, and Israel: between nationalism and politics. Israel Studies, 10(2), 147-167. doi: 10.1353/is.2005.0118.

Kelly, J. (2007) Flowers of Scotland? A sociological analysis of national identities: Rugby union and association football in Scotland. Unpublished PhD thesis, Loughborough University, UK. 
Leith, M. S., \& Sim, D. (2012). Second generation identities: the Scottish diaspora in England, Sociological Research Online, 17(3), 11. doi:

10.5153/sro.2628.

Maclean, F. (2000). Scotland: a concise history. London: Thames and Hudson.

McCarthy, A. (2005). National identities and twentieth-century Scottish migrants in England. In W. L. Miller (Ed.) Anglo-Scottish relations from 1900 to devolution and beyond. (pp. 171-182). Oxford: Oxford University Press.

McCarthy, A. (2007a). Personal narratives of Irish and Scottish migration 192165. Manchester, NY: Manchester University Press.

McCarthy, A. (2007b). The Scots' Society of St Andrew, Hull, 1910-2001:

Immigrant, ethnic and transnational association. Immigrants and Minorities 25(3): 209-233. doi: 10.1080/02619280802407327.

McCrone, D. (1992). Understanding Scotland: The sociology of a stateless nation: London: Routledge. 
Miller, W. L. (2005). Introduction: From last empress to First Minister. In W. L. Miller (Ed.) Anglo-Scottish relations from 1900 to devolution and beyond. (pp. 116). Oxford: Oxford University Press.

Mitchison, R. (1970). A history of Scotland. London: Metheun \& Co.

Moorhouse, H.F. (1984) Professional football and working class culture:

English theories and Scottish evidence. Sociological Review 32: 285-315. doi: 10.1111/j.1467-954X.1984.tb00815.x.

Moorhouse, H.F. (1986) Repressed nationalism and professional football:

Scotland versus England. In J.A. Mangan \& R.B. Small (eds) Sport, culture, society: International historical and sociological perspectives (pp. 52-59).

London: Spon.

Moorhouse, H.F. (1987). Scotland against England: Football and popular culture. International Journal of the History of Sport, 4(2): 189-202. doi: $10.1080 / 09523368708713625$

Moorhouse, H.F. (1994) From zines like these? Fanzines, tradition and identity in Scottish football. In G. Jarvie G \& G. Walker (eds.) Scottish sport 
in the making of the nation: Ninety minute patriots? (pp. 173-194). Leicester: Leicester University Press.

Moorhouse, H.F. (1995) One state, several countries: Soccer and nationality in a 'United' Kingdom. International Journal of the History of Sport, 12(2): 55-74. doi: 10.1080/09523369508713895.

Mycock, A. (2012). SNP, identity, and citizenship: Re-imagining state and nation. National Identities, 14(1): 53-69. doi: 10.1080/14608944.2012.657078.

Pittock, M. (2008) The road to independence? Scotland since the sixties, London: Reaktion.

Rampant Scotland (n.d.) 'Caledonian, Scottish and St Andrew's Societies'. Retrieved from http://www.rampantscotland.com/features/societies.htm.

Royal Scottish Country Dance Society (n.d.) 'Branch \& Group Finder'. Retrieved from https://www.rscds.org/Content.aspx.

Safran, W. (1991) Diasporas in modern societies: Myths of homeland and return, Diaspora, 1(1): 83-99. doi: 10.1353/dsp.1991.0004. 
Sim, D. (2011a). The Scottish community and Scottish organisations on Merseyside: development and decline of a diaspora. Scottish Journal of Historical Studies, 31(1): 99-118. doi: 10.3366/jshs.2011.0008.

Sim, D. (2011b). American Scots: The Scottish diaspora and the USA. Edinburgh: Dunedin Academic Press.

Sim, D. (2012). Scottish devolution and the Scottish diaspora. National Identities, 14(1): 99-114. doi: 10.1080/14608944.2012.657084.

Somers, M. (1994). The narrative constitution of identity: A relational and network approach. Theory and Society, 23(5): 605-649. doi: 10.1007/BF00992905.

Somers, M., \& Gibson, G. (1994). Reclaiming the epistemological 'other': Narrative and the social constitution of identity. In C. Calhoun (Ed.) Social theory and the politics of identity. (pp. 37-99). Oxford: Blackwell.

The Scots' Society of St Andrew, Bedford (n.d.) 'About Us'. Retrieved from http://www.bedscotsoc.org.uk/About\%20Us.html. 
Trevor-Roper, H. (1983). Invention of tradition: The Highland tradition of Scotland. In E. Hobsbawm \& T. Ranger (Eds.) The invention of tradition. (pp. 15-42). Cambridge: Cambridge University Press.

Wembley and District Scottish Association (n.d.) 'History'. Retrieved from http://www.wdsa.co.uk/history.htm.

Whigham, S. (in press) ‘Anyone but England’? Exploring anti-English sentiment as part of Scottish national identity in sport, International Review for the Sociology of Sport. doi: 10.1177/1012690212454359. 